this group in particular, and perhaps patients with DS in general, show a remarkable freedom from the atherosclerosis that, in some degree, inevitably accompanies advancing age. The reasons are not clear. The finding of atherosclerosis in the non-mongol mental defectives suggests that environmental factors such as diet, composition of the water, and the absence of stress are not responsible. Furthermore, the differences between the groups cannot be explained on the basis of lipid concentrations: at the time of study both groups had lower serum lipid concentrations than a group of normal people.

Of the remaining accepted risk factors, blood pressure was slightly but significantly lower in the DS group, and only two of these patients $(3 \%)$ smoked compared with $13\left(19^{\circ}{ }_{0}\right)$ of the controls. While these findings may partly explain the necropsy evidence, it is difficult to accept that they can account for the total absence of atheroma in the DS group and its presence in the controls to a degree consistent with that usually found in the general population.

Probably there are unidentified factors peculiar to DS that confer a noticeable freedom from atherosclerosis. Whether these are haemodynamic or arise from a peculiarity of vessel wall morphology is speculative. It certainly appears on the present evidence that DS provides an atherosclerosis-free model that merits further study.

We thank Dr R C MacGillivray for advice and encouragement, and Dr M S Newton and Mrs J Taylor, MRC Clinical and Population Cytogenetics Unit, for the chromosome studies.

J C M was in receipt of a grant from the Mental Health Foundation (Scottish Division).

\section{References}

1 Richards, B W, editor, in Mental Subnormality: Modern Trends in Research, p 54. London, Pitman, 1970.

${ }^{2}$ Murdoch, J C, et al, Fournal of Clinical Endocrinology, 1977, 44, 453.

${ }^{3}$ Blackburn, H, et al, Circulation, 1960, 21, 1160.

4 Annan, R, and Isherwood, E M, fournal of Medical Laboratory Technology, 1969, 26, 202.

(Accepted 20 May 1977)

\title{
CONDENSED REPORTS
}

\section{Effects of naloxone on pethidine-induced neonatal depression}

\author{
P C WIENER, M I J HOGG, M ROSEN
}

\section{Part I-Intravenous naloxone}

British Medical fournal, 1977, 2, 228-231

\section{Summary}

Infants whose mothers had had pethidine during labour were given either naloxone $40 \mu \mathrm{g}$ or isotonic saline administered intravenously double-blind within one minute of birth. Peak alveolar carbon dioxide tension, carbon dioxide excretion, alveolar ventilation, feeding behaviour, and habituation to a specific sound stimulus were measured regularly up to $\mathbf{4 8}$ hours after birth. Alveolar carbon dioxide tension was significantly lower and alveolar ventilation significantly higher half an hour after birth in the naloxone-treated group than in the saline-treated group, but these differences between the groups were not significant at any other time, and there were no significant differences in sucking frequency or pressure, milk consumption, or habituation to the auditory stimulus.

\section{Introduction}

Administering pethidine to a mother in labour slows down her infant's recovery from birth asphyxia, ${ }^{1}$ lowers oxygen saturation, ${ }^{2}$ and prolongs the time to sustained respiration. ${ }^{3}$ Furthermore, pethidine increases neonatal arterial $\mathrm{PCO}_{2}$ over

Department of Anaesthetics, University Hospital of Wales, Cardiff CF4 4XW

P C WIENER, MD, FFARCS, senior registrar

M I J HOGG, BSC, physicist

M ROSEN, MB, FFARCS, consultant the values in the newborn of unmedicated mothers for up to five hours after birth. ${ }^{4}$ Pethidine also depresses the neonate's feeding behaviour ${ }^{56}$ and habituation to an orientating reflex ${ }^{7}$ for a few days after birth.

Naloxone $40 \mu \mathrm{g}$ administered into the umbilical vein during the first minute after delivery reverses the respiratory depressant effect of pethidine for at least 30 minutes after birth. ${ }^{8}$ But, naloxone, at least in adults, has a relatively short duration of action. ${ }^{9}$ We studied respiration up to the first 48 hours after delivery to see whether naloxone had any longer-lasting effects in infants and we also measured feeding and reflex responses to sound.

\section{Methods}

Written consent was obtained from mothers before labour. Those studied had received pethidine $(100-300 \mathrm{mg})$ during labour. Some had also had $10 \mathrm{ml}$ of $1 \%$ lignocaine infiltrated into the perineum before delivery. Naloxone $(40 \mu \mathrm{g}$ in $1 \mathrm{ml})$ or placebo $(1 \mathrm{ml}$ isotonic saline), chosen blind at random, was administered into the umbilical vein within one minute of birth. The infants included were those of 38-42 weeks' maturity, born spontaneously or after easy forceps delivery, with an Apgar score greater than 7 at one minute, and an umbilical venous $\mathrm{pH}$ greater than $7 \cdot 25$ at birth. Blood was taken from a maternal vein and the umbilical vein at birth. Plasma pethidine concentration was measured by gas chromatography.

The newborn infants were transferred from the labour room to a nursery in which the temperature, lighting, and background noise were constant. Measurements were made (by PCW) half an hour and $4,8,12,24$, and 48 hours after birth. (Feeding started at four hours). Peak alveolar carbon dioxide concentration and carbon dioxide excretion were measured using a rapid-response infrared carbon dioxide analyser (Beckman LB-2) coupled to a peak-hold meter and integrator. ${ }^{10}$ Alveolar ventilation (body temperature and pressure, saturated) and carbon dioxide tension were derived from these measurements. 
Mean $( \pm S D)$ alveolar carbon dioxide tension, carbon dioxide output, and alveolar ventilation in placebo-and naloxone-treated babies up to 48 hours after delivery

\begin{tabular}{|c|c|c|c|c|c|c|c|c|c|}
\hline \multirow{2}{*}{ Time (hours) } & \multicolumn{3}{|c|}{ Alveolar $\mathrm{PCO}_{2}(\mathrm{kPa})$} & \multicolumn{3}{|c|}{$\mathrm{CO}_{2}$ output $(\mathrm{ml} / \mathrm{min} / \mathrm{kg})^{*}$} & \multicolumn{3}{|c|}{ Alveolar ventilation $(\mathrm{ml} / \mathrm{min} / \mathrm{kg})^{\dagger}$} \\
\hline & Placebo & Naloxone & $\mathbf{P}$ & Placebo & Naloxone & $\mathbf{P}$ & Placebo & Naloxone & $\mathbf{P}$ \\
\hline $\begin{array}{r}1 \\
4 \\
8 \\
12 \\
24 \\
48\end{array}$ & $\begin{array}{l}5.6 \pm 1.0 \\
5.6+0.9 \\
5.3 \pm 0.5 \\
5.4 \pm 0.6 \\
5.0 \pm 0.5 \\
5.1+0.5\end{array}$ & $\begin{array}{l}4 \cdot 7+0.6 \\
5 \cdot 4+0.7 \\
5 \cdot 2 \pm 0.5 \\
5 \cdot 2 \pm 0.5 \\
5 \cdot 1 \pm 0.4 \\
5 \cdot 0+0.6\end{array}$ & $\begin{array}{l}0.02 \\
0.4 \\
0.6 \\
0.5 \\
0.7 \\
0.9\end{array}$ & $\begin{array}{l}7 \cdot 1+1 \cdot 0 \\
5 \cdot 8+1 \cdot 4 \\
6 \cdot 0=1.4 \\
6 \cdot 1+1 \cdot 3 \\
6 \cdot 8+1.2 \\
6 \cdot 2+1.1\end{array}$ & $\begin{array}{l}7 \cdot 65 \pm 1.3 \\
5.87 \pm 2.8 \\
6.05 \pm 1 \cdot 7 \\
6 \cdot 27 \pm 1.7 \\
6.67 \pm 1.4 \\
7.01+1.4\end{array}$ & $\begin{array}{l}0.3 \\
0.97 \\
0.98 \\
0.9 \\
0.7 \\
0.2\end{array}$ & $\begin{array}{r}150.27 \pm 37.9 \\
122.1+39 \cdot 0 \\
134.2 \pm 40.6 \\
133.1 \pm 32.3 \\
157.8 \pm 37.0 \\
145.0+36.7\end{array}$ & $\mid \begin{array}{l}185 \cdot 0 \pm 37 \cdot 6 \\
135 \cdot 6+104 \\
136 \cdot 0 \pm 44 \cdot 4 \\
140 \cdot 8 \pm 49 \cdot 9 \\
148 \cdot 6 \pm 21 \cdot 1 \\
160 \cdot 8+36 \cdot 1\end{array}$ & $\begin{array}{l}0.02 \\
0.7 \\
0.9 \\
0.6 \\
0.5 \\
0.3\end{array}$ \\
\hline
\end{tabular}

* Standard temperature and pressure, dry. ${ }^{+}$Body temperature and pressure, saturated.
Conversion: SI to traditional lunits- $\mathrm{PCO}: 1 \mathrm{kPa}=7.5 \mathrm{~mm} \mathrm{Hg}$.

Habituation to an auditory reflex was measured with a sound of $85 \mathrm{~dB}$ around a band at $2000 \mathrm{~Hz}$. The sound, which had been recorded from an audiometer on to a Sony TC-92 cassette recorder, lasted for one second and was emitted at five-second intervals $15 \mathrm{~cm}$ from the infant's ear. The rate of habituation was measured as the time taken until the infant stopped reacting to the sound for five consecutive stimuli. ${ }^{11}$

During a five-minute nutritive test feed, intraoral pressure was measured using a specially made rubber teat with two channels $(1.2 \mathrm{~mm}$ each). One channel was connected to a pressure transducer (National Semi-Conductors Ltd, No LX1602D) and integrated amplifier, while the other channel supplied the feed (Cow and Gate Milk No 1) from a graduated container, the upper level of which was set at the infant's mouth.': A flow-regulating glass capillary tube $(0.5 \mathrm{~mm}$ in diameter, $10 \mathrm{~cm}$ long) interposed a small resistance in the feeding channel; the delivery of milk therefore depended on the sucking pressure of the infant. Mean sucking frequency and mean peak pressure were derived from the pressure recording. The mean consumption of milk ( $\mathrm{ml}$ min $\mathrm{kg}$ ) was measured from the volume emptied from a graduated container during a five-minute test feed.

Statistical analyses were performed using the $t$ test from the Statistical Package for Social Sciences ${ }^{1: 3}$ on a CDC 6600 computer at the University of London.

\section{Results}

The placebo group consisted of 18 infants (mean birthweight $3300+500 \mathrm{~g}$ ) and the naloxone group of 10 infants (mean birthweight $3100 \pm 300 \mathrm{~g}$ ). The difference in numbers arose because 50 ampoules were prepared but the code was broken after 28 babies were treated. The groups were similar in all important respects (table $\mathrm{A}^{*}$ ).

Ventilation measurements-The alveolar $\mathrm{PCO}_{2}$ was significantly lower 30 minutes after birth in the naloxone-treated infants $(P=0.02)$ than in the saline-treated infants but not at any later period (see table). Alveolar ventilation was significantly higher only 30 minutes after birth in the naloxone group $(P=0 \cdot 02)$. There were no important differences in carbon dioxide excretion.

There were no important differences in either habituation to auditory stimuli (table B) or feeding behaviour (table C).

*Copies of tables A-C are available on request from the authors.

\section{Discussion}

These results confirm the finding of Evans $e t \mathrm{al}^{\mathrm{N}}$ that naloxone $40 \mu \mathrm{g}$ given intravenously at one minute after birth lowered the alveolar $\mathrm{PCO}_{2} 30$ minutes after birth. By four hours, however, and up to 48 hours after birth, there were no significant differences between the two groups of infants in any ventilatory measurement, feeding behaviour, or habituation to an auditory stimuli.

These results in normal babies agree with those in adults, in whom morphine-induced respiratory depression was reversed for only 45 minutes by a single intravenous dose of $400 \mu \mathrm{g}$ of naloxone." Since naloxone has a wide therapeutic margin, its action might be prolonged by administering a large intramuscular dose (see part II) or repeated intravenous injections.

\section{References}

James, L A, Anesthesiology, 1960, 4, 405.

- Shiclds, L V, and Taylor, E S, American fournal of Obstetrics and Gynaecology, 1957, 73, 1011.

${ }^{3}$ Moya, F, and Shnider, S A M, American fournal of Obstetrics and Gynaecology, 1964, 8, 1009.

+ Koch, G, and Wendel, H, Acta Obstetrica et Gynaecologica Scandinavica, $1968,47,27$.

Kron, R E, Stein, M S, and Goddard, K E, Pediatrics, 1966, 37, 1012.

"Dubignon, T, et al, Child Development, 1969, 40, 1107.

Brackbill, Y, et al, Anesthesiology, 1974, 40, 116.

${ }^{8}$ Evans, J M, Hogg, M I J, and Rosen, M, British Medical fournal, 1976, 2, 1098.

${ }^{9}$ Evans, J M, Hogg, M I J, and Rosen, M, British Medical fournal, 1974, 2, 589 .

10 Evans, J M, Hogg, M I J, and Rosen, M, British fournal of Anaesthesia, $1977,49,453$.

${ }^{11}$ Ling, D, Ling, A H, and Doehring, D G, fournal of Speech and Hearing Researches, 1970, 13, 9.

1.2 Ellis, R E, personal communication, 1975.

${ }^{13} \mathrm{Nic}, \mathrm{N} \mathrm{H}$, et al, Statistical Package for Social Sciences, 2nd edn. New York, McGraw-Hill, 1975.

(Accepted 20 April 1977)

\author{
Summary \\ Thirty full-term infants whose mothers had had pethidine \\ during labour were given either naloxone $200 \mu$ g or nor- \\ mal saline intramuscularly. The drugs were chosen \\ blindly and administered within one minute of birth. \\ Naloxone produced a significant reduction in mean \\ alveolar carbon dioxide tension and an increase in \\ carbon dioxide excretion and mean alveolar ventilation \\ at all times up to 48 hours after birth. The mean rate of \\ habituation to a repeated auditory stimulus, the mean \\ sucking frequency, the sucking pressure, and the mean \\ consumption of milk were all significantly higher in the
}

naloxone-treated group than in the placebo-treated group up to 48 hours after birth. Intramuscular naxolone therefore seemed to reverse the undesirable effects of pethidine.

\section{Introduction}

Naloxone $40 \mu \mathrm{g}$ when given intravenously to a newborn infant reverses the depression caused by pethidine given to the mother during labour. This effect, however, lasts for only about 30 minutes (see part I). We gave newborn infants a large dose of intramuscular naloxone in an attempt to prolong this action and 